\title{
Consumer Demand and Willingness to Purchase Asian Fruits and Vegetables in Selected Korean Communities in Alabama and Georgia
}

\author{
Dalal Alkordi Youssouf Diabate Robert Zabawa \\ College of Agriculture, Environment and Nutrition Sciences \\ Tuskegee University, Alabama 36088
}

\begin{abstract}
This research analyzed the demand for fresh Asian fruits and vegetables by Korean immigrants in central and east Alabama and west Georgia. The growth of the Korean population in these two areas is due to the opening of two automobile manufacturing plants: Kia in West Point, Georgia in 2009 and Hyundai in Montgomery, Alabama in 2005.The study's objectives were to: 1) establish what demand exists for fresh Asian fruits and vegetables among Korean immigrants in central and east Alabama and west Georgia; and 2) examine the opportunity for a niche market in ethnic vegetables for small and medium-sized farmers. This was accomplished by collecting socioeconomic data on Korean residents in central and east Alabama and west Georgia; estimating consumer buying patterns of Asian fruits and vegetables; and developing a list of Asian fruits and vegetables for potential local farm production as a niche market.A survey instrument was developed and used to collect data on consumer preferences, socio-economic factors, willingness to pay, and buying patterns. The instrument was translated into Korean to be more attractive to the respondents, and images of selected fruits and vegetables were attached. The survey was administered at Korean churches in Lee and Montgomery counties in Alabama, and Muscogee and Troup counties in Georgia. The results demonstrated that $81 \%$ of respondents were willing to buy Asian/Korean fruits and vegetables grown locally, and that $82 \%$ of the participants were willing to pay $(5$ or $>20 \%)$ more for the produce grown by local farmers. A list of preferred fruits and vegetables by the customers was also established.
\end{abstract}

Keywords: Asian fruits and vegetables, Korean community, locally grown produce.

DOI: $10.7176 / \mathrm{JESD} / 10-22-13$

Publication date: November $30^{\text {th }} 2019$

\section{Introduction}

Throughout U.S. history, immigration has played a vital role in bringing significant changes in the country; including economic growth, changes in culture and growth of population. Immigration and its economic, social and political spheres has been subjected to critical analysis and debate since it significantly impacts social mobility, urbanization, employment and voting behavior. And culturally, although they are far from their native countries, immigrants still want to enjoy the food they used to eat in their home countries.

Urban areas are a major source of ethnic stores that sell to different ethnic groups from different parts of the world. Because of rapid globalization and urbanization, ethnic food has become immensely popular. At the same time, the buying behavior of ethnic consumers is not consistent with their positive attitude toward ethnic products. Additionally, the demand for meat products such as mutton, chicken, fish, dairy products, vegetables, fruits and grains has increased among immigrant populations. Researchers have developed several methods to investigate and measure consumer purchase intention and willingness to purchase food products.

Some of these economic and statistical models have been developed to measure the actual or hypothetical willingness of the consumers to purchase products and to predict consumer purchase behavior. Such predictions can lead to changes in producer behavior. For example, a study by Govindasamy et al. (2010) indicated the high demand for ethnic food in the East Coast region. This information can then guide local producers to successfully focus on producing ethnic foods for this the domestic market.

However, it should be noted that the demand for ethnic foods is dependent on consumer food consumption behavior and size of population. Research suggests that Asian-Americans have a strong preference for fresh food products and, therefore, are frequent grocery shoppers. They have strong desire to purchase products that are fresh, unique and diverse, and that would help them to prepare ethnic foods in the comfort of their home. In order to enter the new market, it is essential to identify consumer preferences and behavior.

Consequently, to understand the ethnic food market, it is essential to identify the needs and requirements of Asian-Americans preferences and purchasing behavior. According to Kathleen (2007), consumers strongly prefer to purchase food products that are fresh, of excellent quality and healthy. She also concluded that customers are willing to purchase products that are locally produced. Some researches demonstrate that consumers in United States have strong preference for food products that are locally produced as compared to imported food products. This is specifically true with fresh vegetables and fruits. Additional studies also show that consumers prefer vegetables that are produces locally to prepare vegetarian dishes. 


\section{Problem Statement}

With the rapid increase of the Korean population in central and east Alabama and west Georgia, demand for their traditional fruits and vegetables is on the rise. Thus, the ethnic specialty crop market is a potential source of highvalue crops and value-added opportunities for local U.S. producers.

\subsection{Purpose and Objectives}

The objectives of this study were to: 1) establish what demand exists for fresh Asian fruits and vegetables among Korean immigrants in central and east Alabama and west Georgia; and 2) examine the opportunity for a niche market in ethnic vegetables for small and medium-sized farmers. The study was accomplished by: collecting socioeconomic data on Korean residents in central and east Alabama and West Georgia; estimating consumer buying patterns of Asian fruits and vegetables; and developing a list of potential Asian fruits and vegetables for possible local farm production as a niche market.

\subsection{Justification of the Study}

Farmers are in search of crops of high-value, value-added businesses, and other marketing strategies to increase incomes. Most immigrants are still attached to the foods from their countries of origin. The ethnic specialty crop market is a potential source of high-value crops and value-added opportunities for local U.S. producers.

\section{Literature Review}

The current research problem examined the expansion potential of ethnic crop production in Alabama and Georgia by local farmers based on customer demand from an economic and market-first viewpoint. According to Govindasamy et al. (2010) the ethnic population of the US East Coast has increased significantly and therefore, the demand for preferred fresh food products has increased. Rapid urbanization and the development of urban areas have significantly influenced farmers and agricultural practices. For instance, farmers are opting for highvalue products and marketing practices that help them to increase their profitability and popularity in this expanding market.

Research suggests that farmers markets have experienced a boom because of the growing demand of purchasing locally produced food products. Producing ethnic food crops offers farmers a chance to increase their profitability since they are in demand. Due to the increase in demand for fresh, local food, the number of farmers selling locally produced ethnic food crops has increased in recent years. Several of the farmers have increased their ethnic food crop yield because of increasing demand of fresh, locally produced food crop. A study by Naanwaab (2012) showed that over the last fifteen years, ethnic food products have emerged as a separate market and has grown at an escalating rate. This growth represents a cultural expression of larger ethnic populations that illustrates an increased demand for diverse products as they seek out their traditional foods.

Larger ethnic populations and the growth in their cultural expressions show that product diversity is increasing and consumers have strong preferences to consume traditional food products. The demand for fresh vegetables and fruits has also risen due to a rise in Asian and Hispanic populations in United States, who tend to include more fresh products in their diets as compared to other ethnicities. Ethnic specialty vegetables do not require specialized farming practices and procedures or heavy investments. However, they require a labor force to ensure that they are successfully produced. Ethic food crops are seen as an opportunity for farmers to identify a separate niche market, where they can compete to meet the needs and requirements of the consumers and to increase their profitability.

According to Naanwaab (2012), farmers in United States are growing local ethnic food crops to cater the needs of ethnic consumers and to generate higher revenues. Kathleen (2007) examined the concept of "buying local" and asserts that it is the practice in which consumers eat healthy, organic and fresh food, while at the same time, it supports local agriculture and decreases transportation costs associated with importing food products globally. Products grown in the community can save energy, cultivate the local economy, and help preserve habitat for wildlife.

Purchasing food products that are grown locally helps in supporting the local farming community, helps to protect the environment, improves the local economy and promotes energy efficiency. Local food production is a sustainable practice, which focuses on improving the economy and supporting the community. Since it is essential to understand consumer behavior and demand, food crops are grown accordingly. A telephone survey conducted by the Food Processing Center (2001) found out that locally produced foods were preferred by 500 Nebraska, Missouri, Iowa, and Wisconsin residents. The top three reasons for buying local food was better taste, freshness and support for local farmers.

Ethnic groups can offer local producers a chance to increase their profitability and therefore, they target different ethnicities such as Asian-Americans, African-Americans, and Hispanics. The Asian-Americans are further divided into two dominant subgroups: Indians and Chinese. The Hispanic subgroups include Puerto-Ricans and Mexicans. Knowing that ethnic restaurants are a one fast-growing element in the food industry, ethnic products 
produced by farmers can be supplied to different retailers, wholesalers and restaurants. For example, Gvion and Trostler (2008) showed changes in restaurant menus in the U.S. from the 1960s -1990s as an indicator of ethnic demand.

Gvion and Trostler (2008) also assessed the content and form changes of ethnic dishes in restaurants in order for them to become incorporated into the active dining selection. The authors reached the conclusion that the growing interest in ethnic dishes in the U.S. is an outgrowth of a movement toward becoming a multicultural society. Govindasamy et al. (2010) examined the economic advantages of growing ethnic crops along the East Coast. Their study showed ethnic markets are growing significantly because of urbanization and an increase in ethnic populations.

The Govindasamy et al. study also demonstrated that the demand for ethnic produce would increase substantially and could help producers to develop products according to the needs and requirements of different ethnic groups. Consequently, producers have the opportunity to grow locally produced ethnic food crops to target the needs and requirements of ethnic populations and to improve their agricultural procedures and generate higher income (Govindasamy et al. 2010).

Keiko et al. (2010) conducted a study to understand consumer attitudes towards ethnic food products that are produced by local farmers. They examined the demographic, cultural and social attributes of consumers affected their perception towards the locally produced ethnic food crop. Results showed that consumers are most likely to buy and eat food crop that is locally produced. However, they also reached the conclusion that farmers need to pursue strong and robust market strategy to increase presence in the market.

\subsection{Asian Population Growth in US}

Asian consumers are the primary consumers of the ethnic food market in the United States and their buying power is high. According to Census data (2010), the ethnic population in the United States is increasing significantly, this trend is likely to increase overtime, and the Asian sector is a part of this trend. Humphreys (2004) predicted that the buying power of Asian immigrants would increase substantially as compared to other ethnic groups in United States for the same period of time. The increasing demand of ethnic food crops in the Asian sector, and the scope of growing fresh food products, requires extensive marketing research in order to fully take advantage of the demand from large ethnic markets.

Table 1 shows the change in the Asian immigrant population living in the U.S. from 2000 to 2010 . With the exception of Japanese nationals, Asian populations have all increased. For example, the Indian, Chinese, and Filipino populations have increased by 70,38 , and $38 \%$, respectively. The Korean population, which is the focus of this study, has increased by $32.2 \%$.

There is a growing demand to cater the needs of the Asian-American population since Asian cuisines, more specifically; Chinese, Thai and Japanese food are enjoyed by individuals of other ethnicities. Korean and Vietnamese food cuisines are also becoming popular in United States. According to the report compiled by Data Monitor, ethnic food product attributes are: natural, fresh, organic and healthy as compared to processed American food. Furthermore, ethnic food products have natural flavors that include the use of chili peppers and spices.

Table 1. Percent change in various Asian populations between 2000 and 2010.

\begin{tabular}{lllll} 
Asian & 2000 & 2010 & Change & Percent \\
Asian Alone & $10,242,998$ & $14,674,252$ & $4,431,254$ & 43.2 \\
Chinese & $2,432,585$ & $3,347,229$ & 914,644 & 37.5 \\
Asian Indian & $1,678,765$ & $2,843,391$ & $1,164,626$ & 69.3 \\
Filipino & $1,850,314$ & $2,555,923$ & 705,609 & 38.1 \\
Vietnamese & $1,122,528$ & $1,548,449$ & 425,921 & 37.9 \\
Korean & $1,076,872$ & $1,423,784$ & 346,912 & 32.2 \\
Japanese & 796,700 & 763,325 & $-33,375$ & -4.1 \\
Other Asian & $1,285,234$ & $2,192,151$ & 906,917 & 70.5 \\
\hline
\end{tabular}

According to Govindasamy and Puduri (2009), growing ethnic food products can benefit both local and international crop producers and marketers. In the beverage and food industry, ethnic food cuisines are in demand and, therefore, the demand for ethnic food crops is high. Since ethnic food crops are specialty crops, they are not available at conventional super markets and therefore, consumers are willing to purchase them at a higher price.

The changes in demographics profiles have compelled local and international producers to produce products accordingly in order to compete in the market. Thus, the goal of this study was to study the opportunities that are available for the farmers of Alabama to grow ethnic food crops, based on market perspective and economic benefits. This study was conducted to assist farmers by identifying market trends, to measure the market size and the opportunities that can be offered to them by producing ethnic food crops in local settings. Several farmers have focused on growing special food products because of their high demand and to compete in the market. These farmers cater the needs of a single consumer group. 
In Alabama and Georgia, the ethnic food market can offer local producers and marketers the opportunities to grow and increase their profitability by targeting Asian-Americans, because of rapid growth in their population and their preference for natural, fresh food products, to prepare ethnic cuisines. For many state governments, local farm products can act as a tool for improving the local economy, competitiveness and market shares (Adelaja, Brumfield, \& Lininger, 1990).

Since local producers must understand consumer behavior, they can produce food products that are based on consumer needs and requirements. Furthermore, ethnic food products are preferred by consumers and this can allow producers to improve their agricultural operations and sustain competitive advantage. Small-scale farmers have been forced to target different markets by using specialty marketing to add value to their crops because of intense competition coming from larger scale producers. The market for ethnic food crop is a niche that offers farmers the chance to increase their revenues by remaining in the market since the food products are exclusive.

Excellent opportunities exist for Alabama and Georgia growers due to the growing Korean population and subsequent opportunities offered by their untapped produce demand. According to Science News (2008), Asian vegetables are known to be diverse and are consumed in United States by the Asian-Americans. They are also consumed by other ethnicities because Asian cuisines are immensely popular because of their natural flavor, nutritional value and health benefits.

In larger cities, the demand for ethnic food crops such as herbs, fruits and vegetables is increasing significantly. One reason for the increased demand in cities is the availability of larger ethnic diversity. The procedure for producing a new crop, which is produced locally, is considered to be the joint efforts of the producer and the consumer. A new crop is locally produced in the market based on consumer needs and requirements. Production costs for ethnic vegetables should be carefully considered by producers. Producers may also incur high labor costs during growth and production of ethnic food crops. It is essential that the producers consider the costs of ethnic vegetables in terms of their production. An important discussion is the pricing of a new or specialty crop. On top of possible high seed costs, producers face greater labor costs and lower crop prices compared to non-ethic products. Pricing a new or specialty crop should be based on consumer needs and requirements. The ethnic food product should be available at wholesale and retail prices in order to ensure that the market can afford it.

Ernst and Woods (2010) stated that Asian produce consists of herbs, fruits and vegetables that are used in East Asian cuisines such as Korean, Japanese and Chinese food as well as Southeast Asian cuisines such as Vietnamese, Pilipino, Thai and Indonesian cuisines. The term Asian also refers to the cuisines of South Asians that also includes Indian and Pakistani cuisines. Reports reveal that the on the average, $\$ 1$ of every $\$ 7$ is being spent on purchasing ethnic food products. Smaller producers and famers have several opportunities to meet the demands of the local consumers for Asian vegetables. It is essential that the growers and producers analyze and investigate the demand of Asian vegetables according to the local farmers market.

Marketing Asian vegetables to restaurants can also help farmers to increase their income and increase their presence in the market. Another option is to sell Asian vegetables at premium prices to upscale American restaurants that offer Asian cuisines. In a study done to determine the agri-food industry's opportunities in relation to the changing ethnicity and immigration in Canada, it was found that there exists opportunities to supply unavailable ethnic foods in Canada, substitute ethnic food imports with Canadian-Made products, value-added development of ethnic foods, and the supply ethnic markets abroad (Marrit, 1994).

\section{Methodology}

This study used a survey questionnaire to determine customer demand and willingness to pay for fruits and vegetables in selected Korean communities in Alabama and Georgia (Appendix C). The questionnaire was translated into Korean to be more attractive to the respondents, and images of selected fruits and vegetables were attached. Prior to survey administration, a pilot study was conducted on Korean and Korean-American faculty and staff at the Tuskegee University campus. To achieve the study goals, the survey questionnaire focused on five categories of questions. First, the demographic profiles and composition attributes of Korean customers who resided in the targeted areas. These attributes included gender, occupation, income, household (ages and size), neighborhood, and residency. Second, particular shopping patterns of the Korean surveyed were determined such as all vegetables and fruits expenditure, ethnic produce purchase, ethnic grocery store visitations and other shops to get ethnic produce (distance traveled, frequency, outlet types, etc.). Third, preferences, opinions, and practices which had an influence on the decisions of a customer to purchase Asian produce were examined. Fourth, ethnic produce expenditures of surveyed Korean consumers were quantified to approximate the expenditure of produce for the larger population (Alabama and Georgia). Fifth, spending patterns, the money spent on ethnic produce per visit and the willingness to buy at a premium was examined. In addition, the study assessed the impact of the rapid and steady increase in the Korean populations in Alabama and Georgia due to the Hyundai and Kia manufacturing plants on the demand for fresh Asian produce available. The attached map in Appendix D indicates the location of the two plants. The questionnaire was given to the participants for one week to complete it. The completed questionnaires were collected and the corrections/recommendations were done based on the respondents input. 


\subsection{Data Collection}

Data were collected using convenience sampling. The target population was Koreans living in Montgomery, Lee, and Chambers counties in Alabama, and Muscogee and Troup counties in Georgia. Consumers were asked their frequency of purchases and the vegetable and fruits types they eat. Questions also focused on customer demand and willingness to purchase fruits and vegetables and in what price range. Demographic information collected included the respondent's ethnicity, gender, age, education level and income.

Initially, the car manufacturing plants (Hyundai and Kia) were contacted to administer the survey, but they denied us the access to their employees. As an alternative source for a large number of respondents, Korean churches were approached through their respective pastors. Official request letters from Tuskegee University were sent to pastors of Korean churches in the targeted areas. The pastors agreed to have their congregations participate in the study. The participant churches were: Lee County (Auburn Korean Methodist Church, Auburn Opelika Korean Church and Auburn City Church), Montgomery County (Evergreen Korean Church, Korean First Methodist Church, Korean United Methodist Church and Montgomery Korean Presbyterian Church), Muscogee County (Columbus Korean Methodist Church, Korean Presbyterian Church, Korean Full Gospel Church and Korean Peace Baptist Church) and Troup County (Korean Church of LaGrange, First Baptist Church LaGrange and First United Methodist Church LaGrange.

Based on recommendations from each pastor, the surveys were administered at each location. The survey packet contained a cover letter, a stamped return address envelope, and questionnaire. The total number of distributed surveys was 400 and the returned surveys were 143. Data were analyzed using SPSS and descriptive statistics results were reported. The sampling method and data collection process were documented, the outcomes of the survey and subsequent modeled results were showed and examined, and recommendations and further research were provided. The outcomes that follow are founded on the respondent's socio-demographic specific information in some given circumstances, in addition to buying patterns.

\section{Results and Discussion}

This section presents the survey results categorized under four sub-categories; respondents' shopping patterns, preferences of the selected vegetables and fruits, opinions, and socio-demographic attributes of the respondents. The characteristics of all survey respondents were analyzed.

\subsection{Socio-economic information:}

Based on the survey results, Table 2 shows the respondent's annual-income category after taxes. Twenty five percent of the respondents' income is in the range of $\$ 60,000$ to 79,999 . It is noteworthy that this income range is higher than the U.S. median household income ( $\$ 50,000$ in 2011). While the median household income for the same year is $\$ 41,000$ and $\$ 46,000$ in Alabama and Georgia, respectively (2010). The second largest group of the respondents' income in percent size (18\%) was in the $\$ 40,000$ - 59,999 bracket. The average income of this group corresponds to the U.S. median household income.

The type of residency of the participants was determined and listed in Table 3. Thirty eight percent of respondents live in rural setting, while $32 \%$ and $27 \%$ lived in urban and suburban setting, respectively.

Table 2. Level of income of participants

\begin{tabular}{lll}
\hline Variable & Frequency & Percent \\
\hline Less than $\$ 20,000$ & 9 & 6.3 \\
$\$ 20,000-39,999$ & 24 & 16.8 \\
$\$ 40,000-59,999$ & 26 & 18.2 \\
$\$ 60,000-79,999$ & 35 & 24.5 \\
$\$ 80,000-99,999$ & 14 & 9.8 \\
$\$ 100,000-124,999$ & 9 & 6.3 \\
$\$ 125,000-149,999$ & 3 & 2.1 \\
$\$ 150,000-199,999$ & 6 & 4.2 \\
$\$ 200,000$ or more & 3 & 2.1 \\
No response & 14 & 9.8 \\
Total & 143 & 100.0 \\
\hline
\end{tabular}


Table 3. Residency of participants

\begin{tabular}{lll}
\hline Variable & Frequency & Percent \\
\hline Urban & 45 & 31.5 \\
Suburban & 39 & 27.3 \\
Rural & 54 & 37.8 \\
No response & 5 & 3.5 \\
Total & 143 & 100.0 \\
\hline
\end{tabular}

Table 4 depicts the number of years the respondents have lived in Georgia or Alabama. About 13\% of respondents have lived in Georgia between $(1-20)$ years, and $82.6 \%$ of them have lived in Alabama for the same period. These percentages for the 1-20 years' time period agree with the fact that the Hyundai plant in Alabama was established in 2002, while the Kia plant in Georgia was established in 2009.

Table 4. Number of years that respondents have lived in Georgia or in Alabama

\begin{tabular}{lllll}
\hline & & Georgia & & \multicolumn{2}{c}{ Alabama } \\
Variable & Frequency & Percent & Frequency & Percent \\
\hline $1-10$ & 16 & 11.2 & 114 & 79.8 \\
$11-20$ & 3 & 2.1 & 4 & 2.8 \\
$21-30$ & - & - & - & - \\
$31-40$ & - & - & 1 & 0.7 \\
No response & 124 & 86.7 & 24 & 16.8 \\
Total & 143 & 100.0 & 143 & 100.0 \\
\hline
\end{tabular}

Table 5 illustrates that about $60 \%$ of the participants surveyed are planning to live in their current locations between 1 - 9 years. This percentage indicates that there is an excellent pool of potential Korean buyers of fresh and locally produced Asian/Korean fruits and vegetables.

Table 5. Number of years the respondents plan to live in Georgia or in Alabama

\begin{tabular}{lll}
\hline Variable & Frequency & Percent \\
\hline $1-4$ & 37 & 25.9 \\
$5-9$ & 49 & 34.3 \\
$10-14$ & 5 & 3.5 \\
15 and more & 12 & 8.4 \\
I don't know & 38 & 26.6 \\
No response & 2 & 1.4 \\
Total & 143 & 100.0 \\
\hline
\end{tabular}

According to Table $6,51 \%$ of the households surveyed have an average of four members. The below mentioned socio-demographic attributes of the participants and their households.

Table 6. Size of respondents' household

\begin{tabular}{lll}
\hline Variable & Frequency & Percent \\
\hline 1 & 12 & 8.4 \\
2 & 20 & 14.0 \\
3 & 14 & 9.8 \\
4 & 73 & 51.0 \\
5 & 17 & 11.9 \\
6 & 2 & 1.4 \\
No response & 5 & 3.5 \\
Total & 143 & 100.0 \\
\hline
\end{tabular}

They are important for developing the ethnic profiles of consumer and for targeting specific ethnic markets by producers and retailers. These socio-demographic attributes are further analyzed and also combined with the shopping patterns of participants and their preferences in the following two sections, to establish the importance of such attributes when predicting buying behaviors of consumers.

\section{Buying pattern and places information:}

Table 7 shows the number of times the respondents shop for Asian/Korean fruits and vegetables. The number of times for shopping is distributed over several different ranges. The highest percent of respondents, 33\%, shop more than once a week. The sum of the percentages tops $70 \%$ for respondents who shop once per week, two or more times per week, every two weeks and once a month. This high percentage is an excellent indication that there is good pool of Korean customers who desire fresh and locally produced fruits and vegetables. 
Table 7. Shopping frequency for Asian/Korean produce

\begin{tabular}{lll}
\hline Variable & Frequency & Percent \\
\hline More than once a week & 47 & 32.9 \\
Once a week & 10 & 7.0 \\
Every two weeks & 14 & 9.8 \\
Once a month & 39 & 27.3 \\
Less than once a month & 32 & 22.4 \\
No response & 1 & 0.7 \\
Total & 143 & 100.0 \\
\hline
\end{tabular}

A major element that can impact on the customer's shopping patterns is shopping ability due to store availability. Table 8 illustrates the preferred locations for fruits and vegetables shopping for the respondents. More than half of the participants surveyed do their shopping in a Korean produce stores. The percentage of those who shop in retail supermarkets is $30.1 \%$ and only $10 \%$ shop in farmers' markets and other places.

Table 8. Shopping market for Asian/Korean produce

\begin{tabular}{lll}
\hline Variable & Frequency & Percent \\
\hline Retail Supermarkets & 43 & 30.1 \\
Farmers' Markets & 5 & 3.5 \\
Korean Produce Stores & 85 & 59.4 \\
Other please specify & 8 & 5.6 \\
No response & 2 & 1.4 \\
Total & 143 & 100 \\
\hline
\end{tabular}

Table 9 illustrates the distances that respondents have to drive to purchase Asian/Korean fruits and vegetables. Eighty six percent of respondents have to a drive to Atlanta to purchase Asian/Korean fruits and vegetables. Therefore, the average distances for driving are 75 and 150 miles for respondents who live in West Point, Georgia, and Montgomery, Alabama, respectively.

Table 9. Percentages of respondents who shop at various locations for Asian/Korean produce

\begin{tabular}{lll}
\hline Variable & Frequency & Percent \\
\hline Montgomery & 6 & 4.2 \\
Birmingham & 1 & 0.7 \\
Atlanta & 122 & 85.9 \\
Auburn & 6 & 4.2 \\
Others, specify & 7 & 4.9 \\
No response & 1 & 0.7 \\
Total & 143 & 100 \\
\hline
\end{tabular}

From Table 10, the average weekly expenditures for Asian/Korean fruits and vegetables are over $\$ 20$ with a percentage of $33.6 \%$. The patterns, preferences, and purchases of consumers who purchase Asian/Korean fruits and vegetables warrant further examination in order to determine what influences their decisions to purchase.

Table 10: Average expenditure on Asian/Korean produce by respondents

\begin{tabular}{lll}
\hline Variable & Frequency & Percent \\
\hline Less than $\$ 5$ & 12 & 8.4 \\
$\$ 5-\$ 9$ & 10 & 7.0 \\
$\$ 10-\$ 15$ & 39 & 27.3 \\
$\$ 16-\$ 20$ & 30 & 21.0 \\
Over $\$ 20$ & 48 & 33.6 \\
No response & 4 & 2.8 \\
Total & 143 & 100 \\
\hline
\end{tabular}

Table 11 results illustrates that $53 \%$ of participants answered that they are willing to buy at a 5 to $10 \%$ price increase for locally produced Asian/Korean fruits and vegetables. For the same goods, $21 \%$ of the participants are willing buy at an 11 to $15 \%$ price increase. Thus, $74 \%$ of respondents are willing to pay between 5 to $15 \%$ more to purchase Asian/Korean fruits and vegetables which are produced locally. This high percentage clearly indicates that there is a good market for Asian/Korean produce if produced by local farmers in East and Central Alabama, and West Georgia. 
Table 11: Willingness to pay a premium for Asian/Korean produce

\begin{tabular}{lll}
\hline Variable & Frequency & Percent \\
\hline I would not pay more & 23 & 16.1 \\
$5 \%$ to $10 \%$ more & 76 & 53.1 \\
$11 \%$ to $15 \%$ more & 31 & 21.7 \\
$16 \%$ to $20 \%$ more & 6 & 4.2 \\
More than $20 \%$ & 3 & 2.1 \\
No response & 4 & 2.8 \\
Total & 143 & 100.0 \\
\hline
\end{tabular}

One reasonable way to minimize Asian/Korean produce supply gaps is to grow the demand items nearer to the demand market. Doing so will improve the farmers and customers link as a marketing strategy to guarantee that the produce is of higher quality and fresh. Also, this will meet the basic strategy of fulfilling consumer demand and eliminate drawbacks such as poor quality, limited availability, and lack of freshness. This could rise the availability of the produce in places that might have inadequate supply, improve freshness, reduce marketing time, and increase overall quality (by reducing the magnitude of damage resulting from extensive transport/ shipping/ handling). To test the option's viability, which is to sell produce that is locally-grown, customers were asked if they would buy locally-grown Asian/Korean produce. According to results presented in Table 12, 85\% of respondents wished to purchase such produce. Below 12\% were "not sure" about their desire (or lack of) to purchase such produce, while below 3\% had no desire to buy such produce. The high positive answers and the low negative answers, confirms the hypothesis that selling of produce that is locally grown in this area might become a successful enterprise for local farmers and retailers (as per the consumer demand perspective).

Table 12: Need for locally grown Asian/Korean produce

\begin{tabular}{lll}
\hline Variable & Frequency & Percent \\
\hline Yes & 122 & 85.3 \\
No & 4 & 2.8 \\
Not sure & 15 & 10.5 \\
No response & 2 & 1.4 \\
Total & 143 & 100.0 \\
\hline
\end{tabular}

In order to examine the respondents' ability to acquire Asian/Koreans fruits from sources other than Korean produce shops, we surveyed their willingness to grow them at home. Forty four percent of respondents indicated that they are not going to grow Asian/Korean fruits and vegetables at home for personal consumption while $32 \%$ said they will do so.

Table 13: Willingness of respondents to grow Asian/Korean produce at home for personal consumption

\begin{tabular}{lll}
\hline Variable & Frequency & Percent \\
\hline Yes & 46 & 32.2 \\
No: explain why not & 63 & 44.1 \\
No response & 34 & 23.8 \\
Total & 143 & 100.0 \\
\hline
\end{tabular}

According to Table 14, $86 \%$ of the participants spending in Asian/Korean restaurants ranged from $\$ 10$ to over $\$ 15$ per visit. This high percentage is an excellent indication that Korean populations in East, Central Alabama and West Georgia have high preference for their native diet.

Table 14: Money spent on Asian/Korean restaurant per visit

\begin{tabular}{lll}
\hline Variable & Frequency & Percent \\
\hline Less than \$ 5 & 2 & 1.4 \\
$\$ 5-\$ 9$ & 10 & 7.0 \\
$\$ 10-\$ 15$ & 58 & 40.6 \\
Over \$ 15 & 65 & 45.5 \\
Other & 6 & 4.2 \\
No response & 2 & 1.4 \\
Total & 143 & 100.0 \\
\hline
\end{tabular}

Table 15 presents the average weekly expenditure on Asian/Korean produce per household. The result shows that $89 \%$ of respondents spend between $\$ 10$ - \$20 per week for fruits and vegetables. 
Table 15: Average weekly expenditure on Asian/Korean produce per household

\begin{tabular}{lll}
\hline Variable & Frequency & Percent \\
\hline Less than \$ & 1 & 0.7 \\
$\$ 5-\$ 9$ & 13 & 9.1 \\
$\$ 10-\$ 15$ & 38 & 26.6 \\
$\$ 16-\$ 20$ & 88 & 61.5 \\
No response & 3 & 2.1 \\
Total & 143 & 100.0 \\
\hline
\end{tabular}

Table 16 presents the need for better selection of Asian/ Korean fruits and vegetables in the local area grocery stores. Ninety three of respondents said that they need a better Asian/Korean vegetables and fruits selection in their local area grocery store. This positively high percentage is strong corroboration that Asian/Korean produce presents an excellent market opportunity for local farmers.

Table 16: Need for better selection of Asian/Korean fruits and vegetables in the local area grocery stores

\begin{tabular}{lll}
\hline Variable & Frequency & Percent \\
\hline Yes & 133 & 93.0 \\
No & 2 & 1.4 \\
Not Sure & 7 & 4.9 \\
No response & 1 & 0.7 \\
Total & 143 & 100.0 \\
\hline
\end{tabular}

One of our goals for this study was to develop a list of the most-demanded Asian/Korean produce by the Korean community in Central, East Alabama and West Georgia. Using the picture-based section of the survey (Appendix C), the list of the most-demanded Asian/Korean produce was narrowed and it is presented in Table 17. The main criterion on which the list was developed was the participants' choice for the average quantity of produce they need per month. One advantage of developing this list was so that crop and soil scientists at Tuskegee University could test the feasibility of growing these produce in local soil and weather conditions in Alabama and Georgia. The average price for the produce is also presented in Table 17. The average price permits determination of the cost effectiveness of locally producing the fruits or vegetables versus the cost of importing it.

Table 17. List of most-demanded Asian/Korean produce based on participants' response.

\begin{tabular}{|c|c|}
\hline Produce & $\begin{array}{c}\text { Average } \\
\text { Quantity/Month }\end{array}$ \\
\hline
\end{tabular}

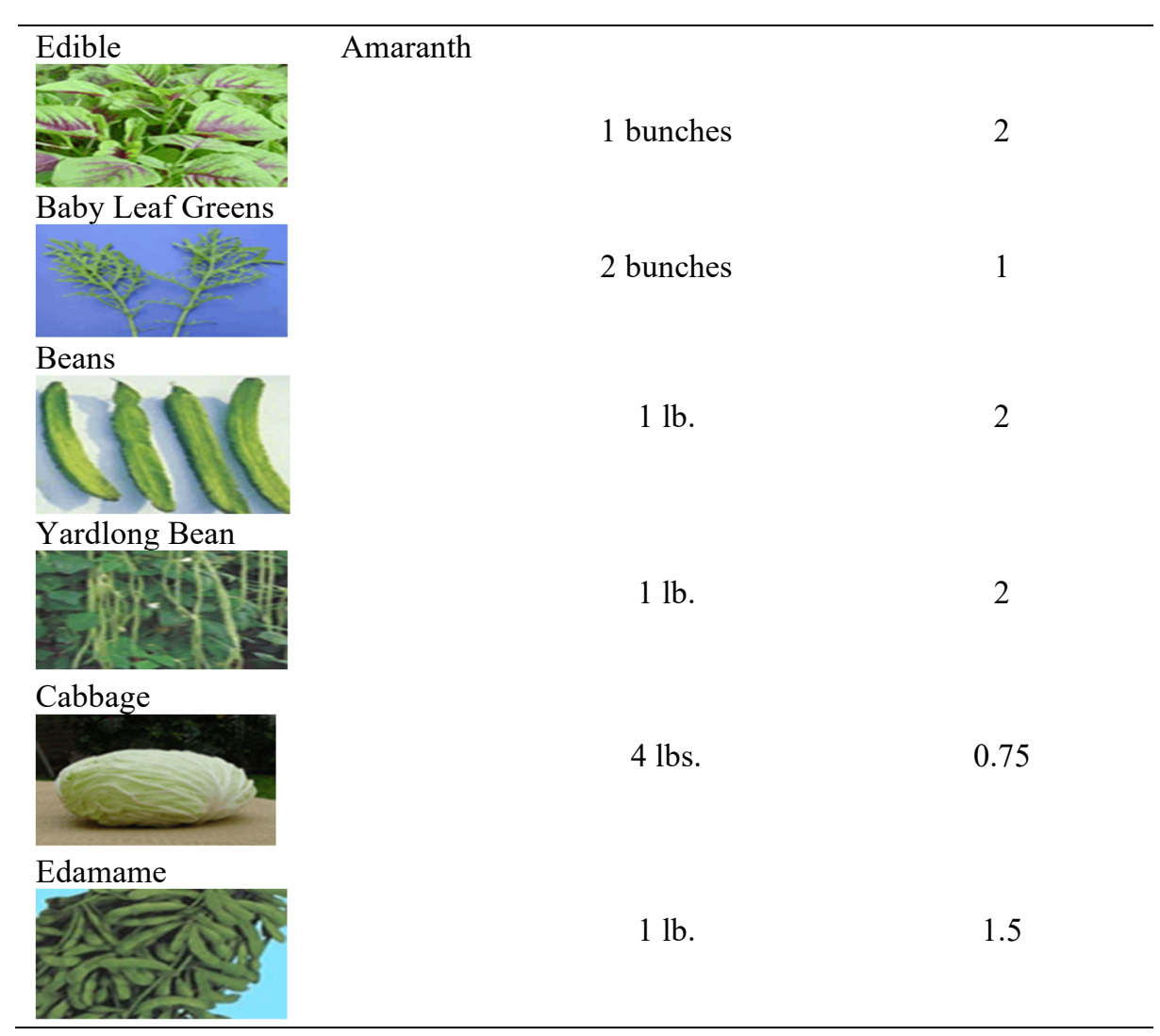


Average Price

(\$)

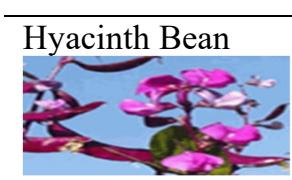

Edible Burdock

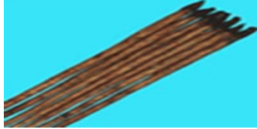

Chinese Cabbage

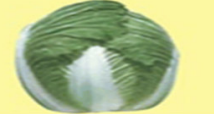

$3 \mathrm{lbs}$

Pei Tsai

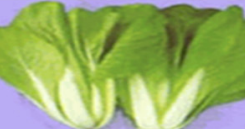

Green Baby Pak Choy

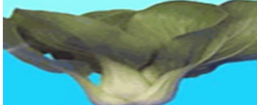

$1 \mathrm{lb}$.

\section{Carrot}

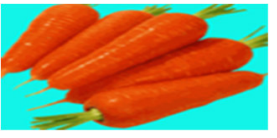

3 lbs.

4

Oriental Cucumber

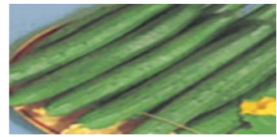

4 lbs.

Oriental Eggplant

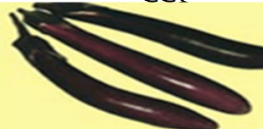

$1 \mathrm{lb}$.

Lettuce

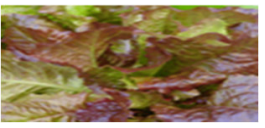

4 bunches

Calabash Gourd

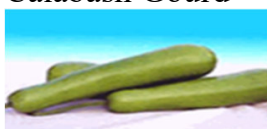

$2 \mathrm{lbs}$.

1

Komatsuna

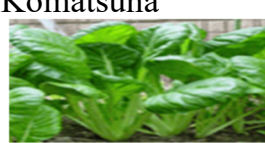

1 bunches 


\section{Produce}
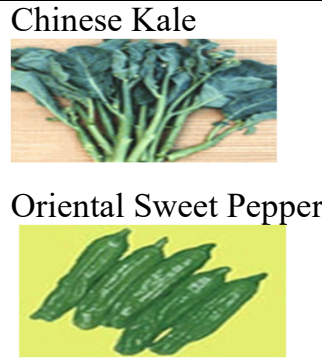

Hot Pepper

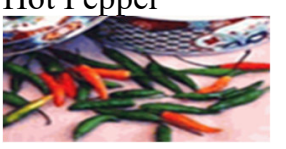

Oriental Spinach

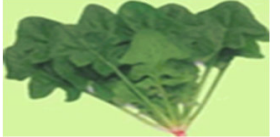

Oriental Squash

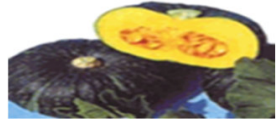

Tomato

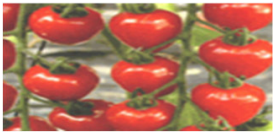

Watermelon

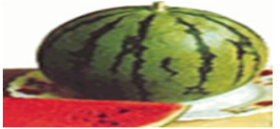

Average

Quantity/Month

2 bunches

2

$1 \mathrm{lbs}$.

$1 \mathrm{lbs}$.

1 bunches

$2 \mathrm{lbs}$.

3

$3 \mathrm{lbs}$.

2

$5 \mathrm{lbs}$.

\section{Source: Demographics and the Marketing of Asian Ethnic Produce in the Mid-Atlantic States (2006)}

\section{Conclusion and Recommendations}

The results of this study confirmed our hypothesis that there exists a possible vegetables and fruits market for Asian produce produced locally. The evidence found can be used to provide business opportunities for local farmers and guidance for retailers, public policy makers, and commercial farmers in Alabama and Georgia in addressing niche market opportunities in the Asian/Korean produce sector. Our results corroborate similar studies conducted in other regions of the US (Geisler, 2011; Jia, 1996; Keiko, 2010; Stewart, 2004). The most demanded fruits and vegetables were identified, along with potential local farmer markets in the targeted counties.

Potential retail centers are presented in maps illustrated in Appendices E, F and G. The results further showed that respondents bought Asian fruits and vegetables from Korean specialized farmer markets. These markets are mostly located in the Atlanta Metropolitan area, radii of 70-150 miles for the Koreans living in West Georgia and East Alabama. It is evident that it will be more convenient for these Koreans to purchase their fruits and vegetables from local farmer markets, thereby, saving them the time and cost of traveling to Atlanta.

Finally, it is recommended that the results of this research should be used as the cornerstone for exploratory research projects which involves, growing Asian/ Korean crops in Alabama and Georgia. This study has developed a list of the most-demanded Asian fruits and vegetables. Moreover, it is highly recommended that commercial production of these fruits and vegetables should be founded on further research that examines the yield determination, production feasibility, and net profitability estimates in Alabama and Georgia. Climatical, pedological and environmental conditions must also be considered when conducting these studies.

The results from this study will be used by the George Washington Experimental Station at Tuskegee University to evaluate the feasibility of growing the selected Asian fruits and vegetables. It will include production conditions and the economic costs. In addition, their studies will include the calculation of the carbon footprint 
from the growing of these products domestically versus importing them.

\section{Appendices}

Appendix D

Map 1: Targeted areas in Alabama and Georgia

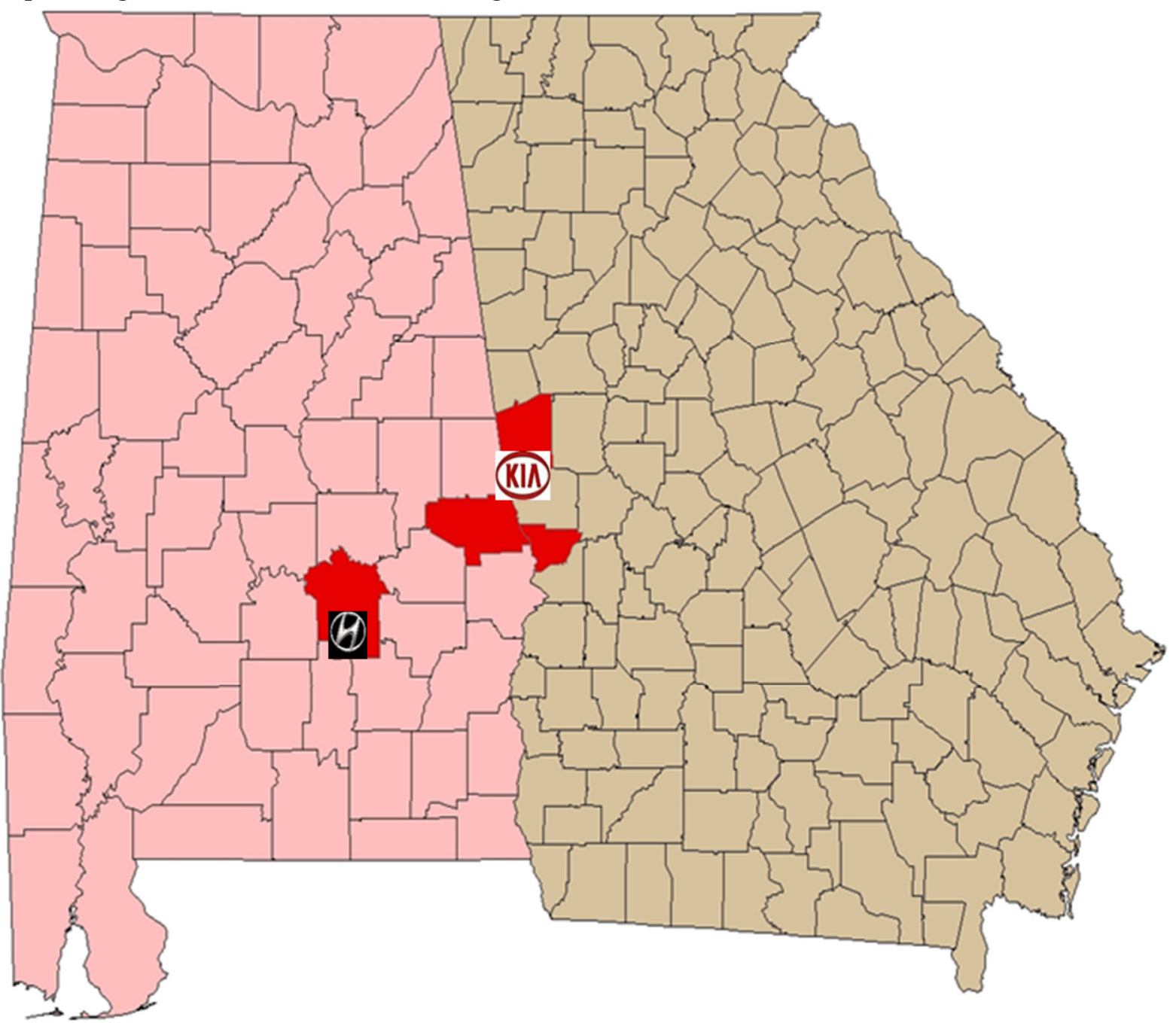

Target Areas

Georgia

Alabama
Hyundai Plant

KIA Kia Plant 
Appendix E

Map 2: Approximate number of Farmer Markets in the Targeted areas

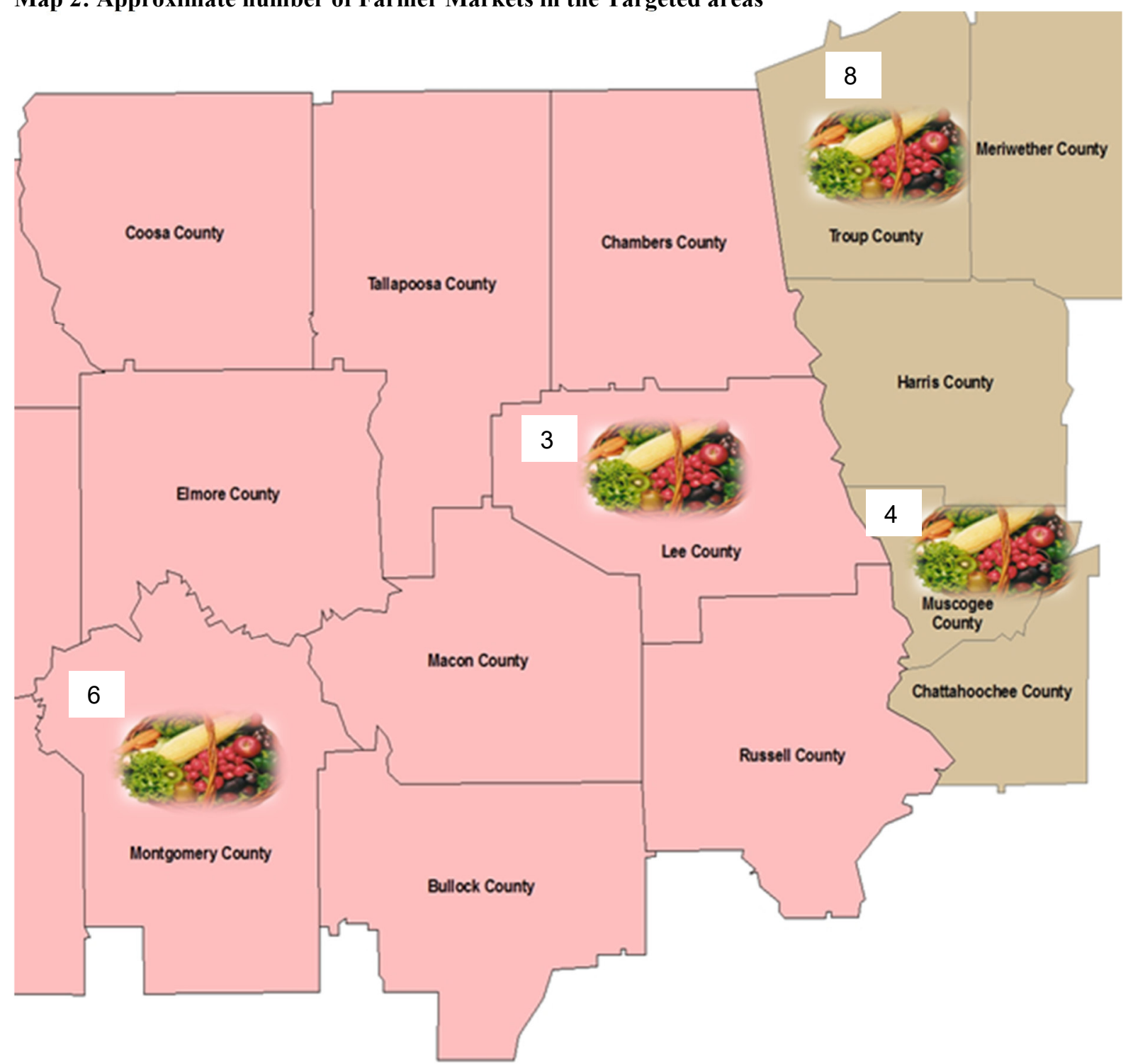

Alabama

Georgia

\# Farmer Market 


\section{Appendix F}

Map 3: Korean populations in close proximity to Farmers Markets in Lee and Montgomery counties in Alabama

\section{Farmers Markets in Lee County (Alabama)}
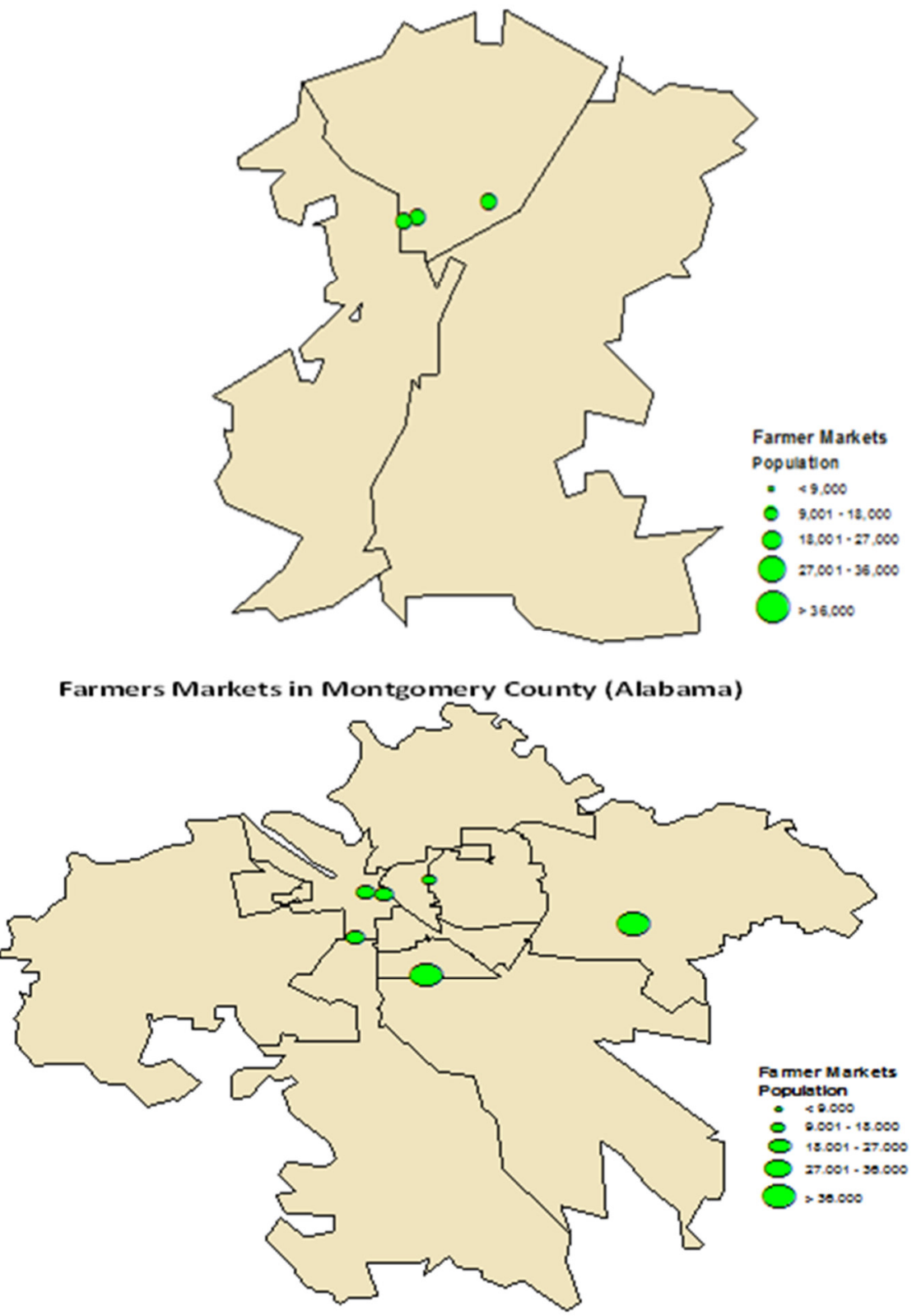


\section{Appendix G}

Map 4: Korean populations in close proximity to Farmers Markets in Troup and Muscogee counties in Georgia

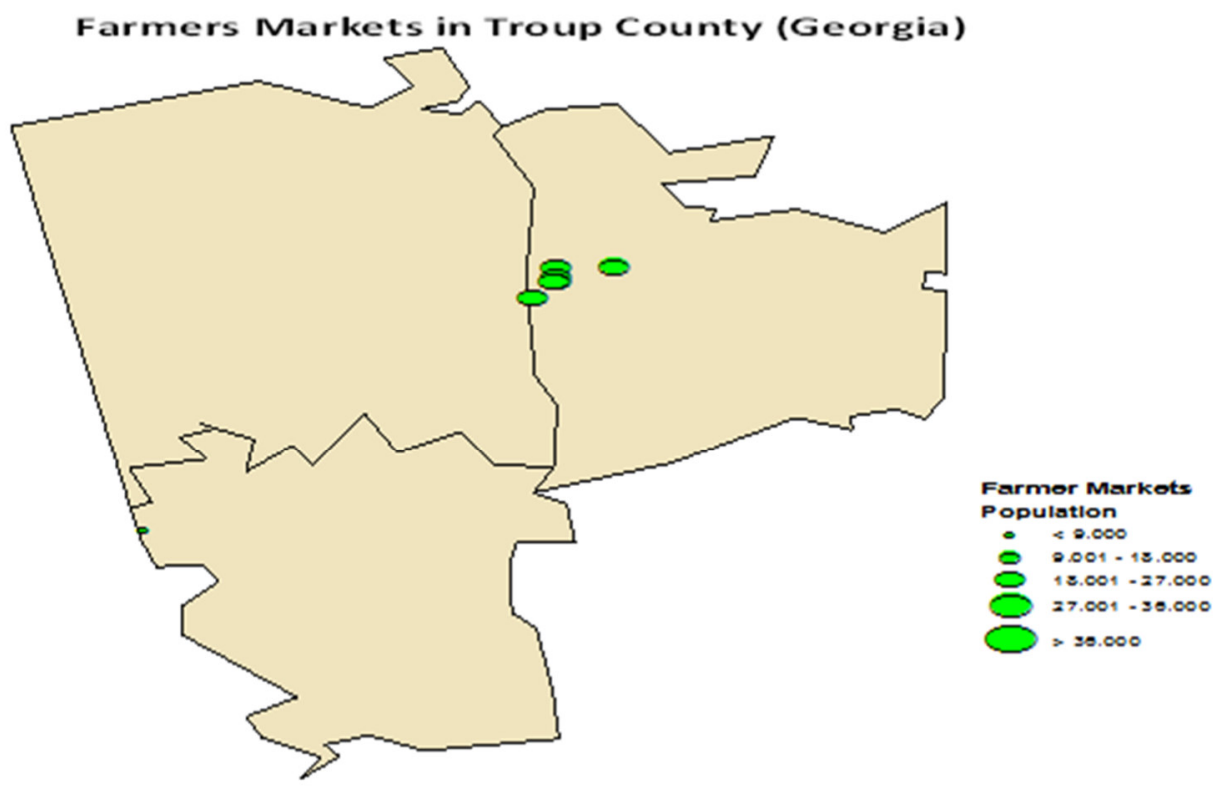

Farmers Markets in Muscogee County (Georgia)

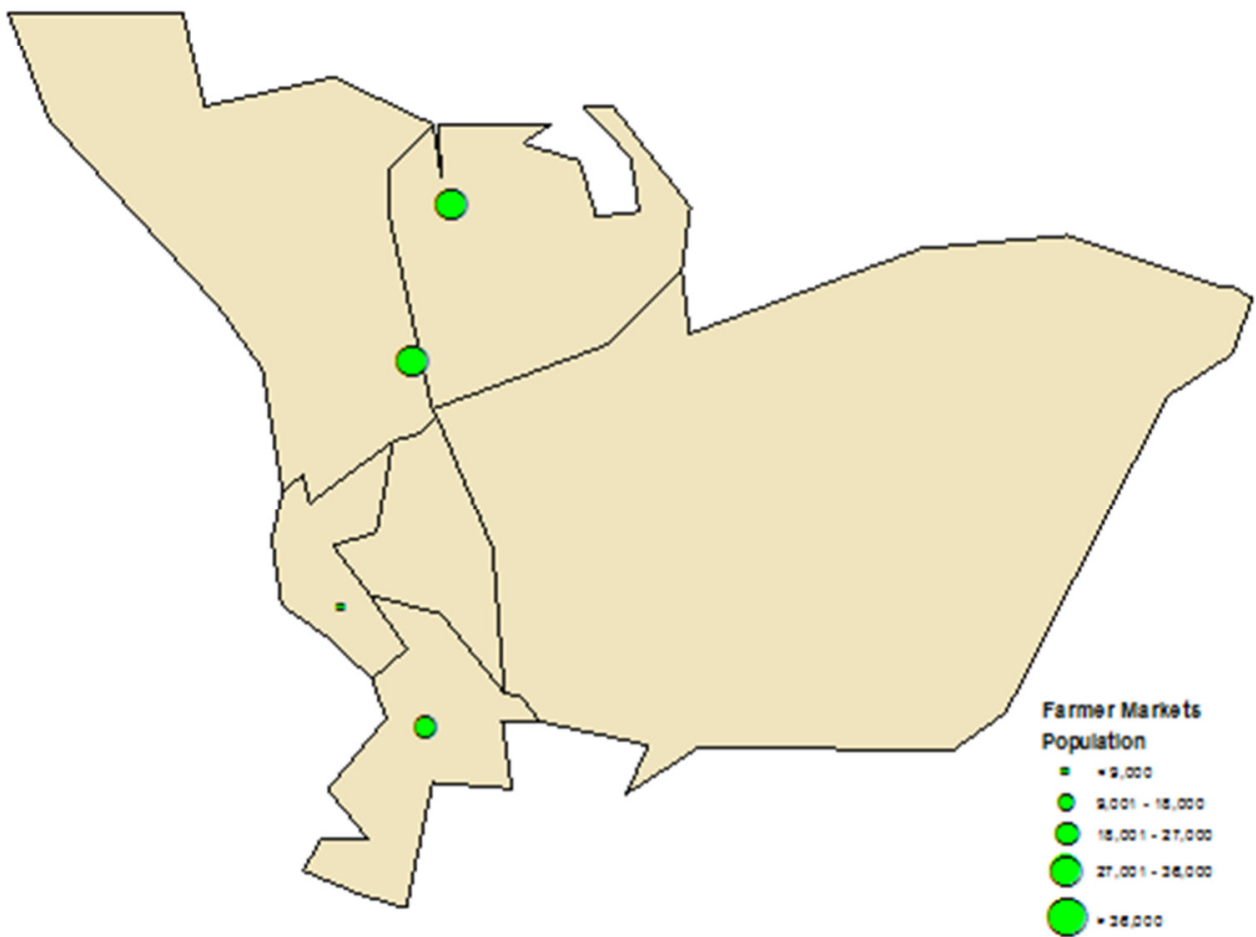

\section{References}

(2010). US Census Bureau.

Retrieved 10 April 2012, from http://www.census.gov/prod/cen2010/briefs/c2010br-11.pdf

Adelaja, Adesoji O, Brumfield, Robin G, \& Lininger, Kimberly. (1990). Product differentiation and state promotion of farm produce: An analysis of the Jersey Fresh tomato. Journal of Food Distribution Research, 21(3), 73-85.

Agri-Food, Service Trade. (2008). United States Ethnic Food Market: Opportunities for Canadian Agri-Food Exporters. Canada.

Center, Agricultural Marketing Resource. (2010). Ethnic foods market. Retrieved July 7, 2013 
Cook, R.L. (2001). The U.S. Fresh Produce Industry: An Industry in Transition. University of California, Division of Agriculture and Natural Resources.

Ernst, M., Woods, T. (2010). Marketing Asian Produce. University of Kentucky: University of Kentucky Cooperative Extension Service. Crop Diversification and Biofuel Research Education Center

Food Processing Center, Institute Of Agriculture and Natural Resources, University of Nebraska - Lincoln. (2001). The North Central Initiative For Small Farm Profitability

Geisler, M. (2011). Ethnic Foods Market Profile. Iowa State University: Agricultural Marketing Resource Center, USDA Rural Development.

Govindasamy, R., A. Nemana, V. Puduri, K. Pappas, B. Schilling, J. E. Simon, R. V. Vranken, and L. Brown. (2006). Demographics and the Marketing of Asian Ethnic Produce in the Mid-Atlantic States. New Jersey Agricultural Experiment Station P-02903-2-07.

Govindasamy, R., R. V. Vranken, W. Sciarappa, A. Ayeni, V. S. Puduri, K. Pappas, J. E. Simon, F. Mangan, M. Lamberts, and G. McAvoy. (2010). Ethnic Crop Opportunities for Growers on the East Coast: A Demand Assessment. Journal of Extension, 48, 1-6.

Grubinger, V. (2010). Ten reasons to buy local food, Growing for Market' newsletter.

Gvion, L., Trostler, N. (2008). From Spaghetti and Meatballs through Hawaiian Pizza to Sushi: The Changing Nature of Ethnicity in American Restaurants. The Journal of Popular Culture, 41(6), 950-974. doi: 10.1111/j.1540-5931.2008.00559.x

Jekanowski, M. D., R. W. Daniel, II, and A. S.William. (2000). Consumers' Willingness to Purchase Locally Produced Agricultural Products: An Analysis of an Indiana Survey. Agricultural and Resource Economics Review, 29(1), 43-53.

Jia, W., M. Witt, and J. Strang. (1996). Growing and marketing Chinese vegetables in central Kentucky. Progress in New Crops, 496-500.

Kathleen, P. (2007). An Analysis of Food-Chain Demand for Differentiated Farm Commodities: Implications for the Farm Sector. USDA Rural Business and Cooperatives Program.

Keiko, G., J. Phillips, and S. Bianco-Simeral. (2010). Consumers' Perceptions of Locally Grown Ethnic Food Products at Farmers' Markets. Journal of Nutrition Education and Behavior 42.

Kotler, Philip; Keller, Kevin Lane. (2009). Marketing Management: Pearson Education India.

Lanford, B. (2011). Local Food: Does It Matter What We Eat? Extension Agent, Community and Economic Development, 1-4.

Lohr, S. L. (1998). Sampling design and analysis New York: Brooks/Cole Publishing.

Marritt, R. and B. Sundue. (1994). Opportunities in Selected Ethnic Markets in Canada, The Effect of Immigration and Ethnicity on the Demand for Food in Canada.

Naanwaab, C., and Y. Osei. (2012). Demand for Fresh Vegetables in the United States: 1970-2010. Economics Research International. , 1-11.

News, Science. (2008). Bring On the Pak Choi: Consumers Interested In Trying More Asian Vegetables.

Patten, M. (2009). Understanding research methods, an overview of the essentials. : . Glendale, CA: Pryczak Publishing.

Roheim, C. A., D. Catherine, K. Robert, J. Aaron, A. McCluskey, J.Johnson, I. Pardoe, F. Jeannine, and H. Zhao. (2007). Rhode Island Consumers' Preferences for Locally-Produced Food: Report on Results from a 2006 Survey. USDA/CSREES National Research Initiative Program

Stewart, H, B. Noel, B. Sanjib and N. Rodolfo M. (2004 ). The demand for food away from home full- service or fast food (829). USDA, Economic Research Service, Agricultural Economic

Tubene, S. (2002). So, You Thought Eggplants Were Only Purple: Growing and Marketing Ethnic and Specialty Vegetables in the Mid-Atlantic Region. Maryland: Maryland cooperative extension.

\section{Acknowledgments}

This research was supported in part by the George Washington Carver Agricultural Experiment Station, Tuskegee University, USDA Office of Advocacy and Outreach Socially Disadvantaged Farmers and Ranchers Program, and USDA NIFA grant agreement \#ALX-010. The authors also wish to express their appreciation for the assistance of the Korean churches in Auburn, Opelika and Montgomery, Alabama and in Lagrange, Georgia. 